\title{
Publisher Correction: Dependence of economic impacts of climate change on anthropogenically directed pathways
}

Jun'ya Takakura (D), Shinichiro Fujimori@, Naota Hanasaki (D), Tomoko Hasegawa (D, Yukiko Hirabayashi (D, Yasushi Honda, Toshichika lizumi (D), Naoko Kumano, Chan Park (1), Zhihong Shen (D), Kiyoshi Takahashi, Makoto Tamura, Masahiro Tanoue, Koujiro Tsuchida, Hiromune Yokoki, Qian Zhou, Taikan Oki@D and Yasuaki Hijioka

Correction to: Nature Climate Change https://doi.org/10.1038/s41558-019-0578-6, published online 25 September 2019.

In the version of this Letter originally published, in the $y$ axis label of Fig. $4 \mathrm{~b}$ the units were incorrectly given as '(\% of GDP $\left.{ }^{\circ} \mathrm{C}\right)^{-1}$ '; they should have been ' $\%$ of GDP per $\left.{ }^{\circ} \mathrm{C}\right)$ '. In addition, Supplementary Datasets $1-4$ and Computer Code 1 were initially provided as separate files; these have now been combined into a single zip file. The online versions of this Letter have been amended accordingly. 